\title{
Optimization of Fuzzy Control for Magnetorheological Damping Structures
}

\author{
Jianguo Ding, ${ }^{1}$ Xin Sun, ${ }^{2}$ Lifeng Zhang, ${ }^{1}$ and Jiaoyan Xie ${ }^{1}$ \\ ${ }^{1}$ School of Science, Nanjing University of Science and Technology, Nanjing, China \\ ${ }^{2}$ Guang'an Municipal Bureau of Housing and Urban-Rural Development, Sichuan, China \\ Correspondence should be addressed to Jiaoyan Xie; xjy239@sina.com
}

Received 20 April 2017; Accepted 5 July 2017; Published 9 August 2017

Academic Editor: Evgeny Petrov

Copyright (c) 2017 Jianguo Ding et al. This is an open access article distributed under the Creative Commons Attribution License, which permits unrestricted use, distribution, and reproduction in any medium, provided the original work is properly cited.

\begin{abstract}
Due to the influence of nonlinearity and time-variation, it is difficult to establish an accurate model of a magnetorheological damping structure that adopts semiactive control. Fuzzy control is a relatively appropriate control method, but fuzzy control design is susceptible to human subjective experience, which will decrease the control effect. This paper proposes new fuzzy control rules based on a genetic algorithm (GA) and particle swarm optimization (PSO) and performs a numerical simulation for a three-layer reinforced concrete frame structure under conditions of an uncontrolled structure, fuzzy control, fuzzy control optimized by GA, fuzzy control optimized by PSO, and GA-optimized FLC control (GA-FLC) proposed by Ali and Ramaswamy (2008). The results show that (1) the fitness values of the convergence of the two types of optimized fuzzy control are close. The speed of the convergence of the fuzzy control optimized by PSO is faster than that of the fuzzy control optimized by GA, but its running speed is slower. (2) Comparing the acceleration and displacement of the structure under the conditions of three different seismic waves, the effect of the optimized fuzzy control is better than that of the human experience fuzzy control and GA-FLC.
\end{abstract}

\section{Introduction}

Earthquakes seriously threaten the safety of civil engineering structures. The search for an effective control method to reduce the response of engineering structures under seismic action and improving the structural aseismic ability is always a significant research subject in the field of civil engineering. Magnetorheological dampers (MR dampers) are vibration dampers that take a magnetorheological liquid as the working medium, and it can adjust the magnetic field strength through changing the magnet exciting the coil current and then changing the shear stress of the magnetorheological liquid and the damping force of the MR damper. MR dampers have a wide damping force adjustment range, low power consumption, fast response speed, simple structure, and other advantages, so they have promising prospects of application in the field of civil engineering.

The parameters of the MR damper change with the external magnetic field in a strongly nonlinear manner, so it is difficult to establish an accurate model, and it is hard to meet practical engineering needs when adopting a traditional control algorithm to control the MR damper [1]. Fuzzy control is a control algorithm that does not need an accurate model for the controlled object, is not sensitive to changes in the parameters, and possesses good robustness. For a magnetorheological damping structure, fuzzy control is a relatively ideal control method. Bitaraf et al. [2] utilized fuzzy control to control the MR damper, and the results show that fuzzy control can effectively decrease the displacement and acceleration responses of the system. Kim and Roschke [3] carried out isolation control for a bridge by applying an MR damper with fuzzy control, and the effect is remarkable. Ali and Ramaswamy [4] utilized fuzzy control to control an MR damper, and his numerical simulation achieved great results.

The membership function of the fuzzy control and the fuzzy rules generally depend on the knowledge and experience of the experts, and output is obtained by fuzzy reasoning, so fuzzy control cannot completely reflect the relationship between the input and output, and this will influence the effect of the control. To improve the effect of the fuzzy 
control, it is necessary to perform optimization. Ahlawat and Ramaswamy [5], Dounis et al. [6], and Ali and Ramaswamy [7] utilized GA to optimize fuzzy control under the premise of the same fuzzy control rules, and the effects, as shown by a numerical simulation of the magnetorheological damping structure, are remarkable. Ranjani and Murugesan [8] utilized PSO to optimize the parameters of fuzzy control and achieved obvious effects in the velocity control. Marinaki et al. [9] utilized PSO to optimize fuzzy control and performed a numerical simulation of smart beams. The result shows that the effect of the optimized fuzzy control is much better than that of the human experience fuzzy control.

The genetic algorithm (GA) and particle swarm optimization (PSO) are both random intelligent search algorithms, but the way in which they determine their next generation is different. The genetic algorithm will code the question parameters as chromosomes and perform selection, crossover, and mutation to generate chromosomes that conform to the goal of the optimization. Particle swarm optimization is easy to operate and implement and can take advantage of the cooperation and competition between particles to optimize the search. These two methods do not rely significantly on the question and can obtain global optimal solutions, so they can be used to optimize the fuzzy control and provide strong help for establishing the fuzzy control system.

This paper proposes new control algorithms based on the genetic algorithm (GA) and particle swarm optimization (PSO) to optimize the fuzzy control rules and performs a numerical simulation on a three-layer reinforced concrete frame structure under conditions of an uncontrolled structure, fuzzy control, fuzzy control optimized by GA, and fuzzy control optimized by PSO.

1.1. Mechanical Model for MR Damper. The Bingham model considers an MR damper to be equivalent to a friction element and a viscous damper in parallel, and it can adequately reflect the nonlinear force-displacement and force-velocity characteristics; this paper adopts the Bingham model. Hypothetically, the shear stress is $\tau$, the magnetorheological kinetic viscosity coefficient is $\eta$, the shear strain rate is $\dot{\gamma}$, and the shear yield stress that is relevant to the magnetic field strength is $\tau_{y}$, so that its stress-strain relationship is

$$
\tau=\eta \dot{\gamma}+\tau_{y} \operatorname{sgn}(\dot{\gamma}) .
$$

If the piston length of the MR damper is $L$, the inner diameter of the cylinder is $D$, the active area of the piston is $A_{p}$, damping hole width is $D_{h}$, and the displacement of the piston relative to the cylinder is $u(t)$; the damping force formula of the MR damper can be expressed as

$$
F=\frac{12 \eta L A_{p}^{2}}{\pi D D_{h}^{3}} \dot{u}(t)+\frac{3 L \tau_{y} A_{p}}{D_{h}} \operatorname{sgn}[\dot{u}(t)] .
$$

In addition, the shear yield stress $\tau_{y}$ is relevant to the magnetic field strength, so $\tau_{y}$ is a function of the control current. The relationship between them can be expressed as

$$
\tau_{y}=A_{1} e^{-I}+A_{2} \ln (I+e)+A_{3} I .
$$

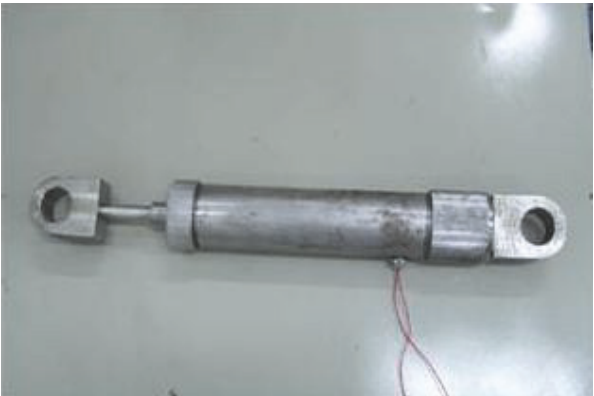

Figure 1: Picture of the MR damper.

TABLE 1: Structural parameters of the MR damper.

\begin{tabular}{lc}
\hline Parameter & Value \\
\hline Piston length $L$ & $400 \mathrm{~mm}$ \\
Inner diameter of the cylinder $D$ & $100 \mathrm{~mm}$ \\
Active area of the piston $A_{p}$ & $6.6 \times 10^{3} \mathrm{~mm}^{2}$ \\
Damping hole width $D_{h}$ & $2 \mathrm{~mm}$ \\
Apparent density of the MR fluids $\eta$ & $1.0 \mathrm{~Pa} \cdot \mathrm{s}$ \\
\hline
\end{tabular}

In this formula, $A_{1}, A_{2}$, and $A_{3}$ are the coefficients of the performance of magnetorheological fluids and $e$ is a natural constant.

The structural parameters of the MR damper this paper adopts are shown in Table 1.

The MR damper that this paper develops is shown as Figure 1.

\section{Test of the MR Damper Performance}

The MR damper this paper adopts is tested under conditions of different control currents, different loading amplitudes, and different loading frequencies, and the force-displacement and force-velocity hysteresis curves of the MR damper are acquired. In the test, the input displacement changes as a sine wave.

2.1. Analysis of the MR Damper Performance. Under the following three sets of experimental conditions, data on the force, displacement, and velocity of the MR damper are acquired, and the mechanical characteristic curves are plotted.

When the loading amplitude is $9 \mathrm{~mm}$, the loading frequency is $0.5 \mathrm{~Hz}$, and the input currents are $0 \mathrm{~A}, 0.5 \mathrm{~A}$, $1 \mathrm{~A}, 1.5 \mathrm{~A}$, and $2 \mathrm{~A}$, the force-displacement and force-velocity hysteresis curves of the MR damper are shown as Figure 2.

As seen from Figure 2, the peak damping force of the MR damper increases with the current. When the current increases from $0 \mathrm{~A}$ to $2 \mathrm{~A}$, the peak damping force increases from $3.66 \mathrm{kN}$ to $14.37 \mathrm{kN}$, but the rate of increase is gradually reduced. Hence, the magnetorheological fluid tends to a saturated shear yield strength with the increasing current, and the damping force of the MR damper gradually tends to a maximum. 


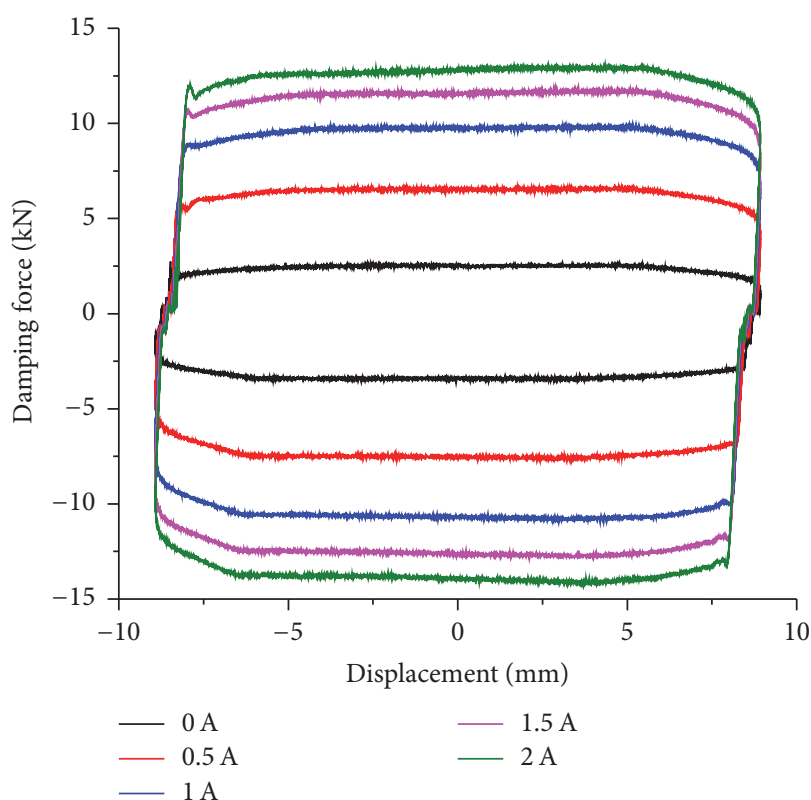

(a) Force-displacement curve

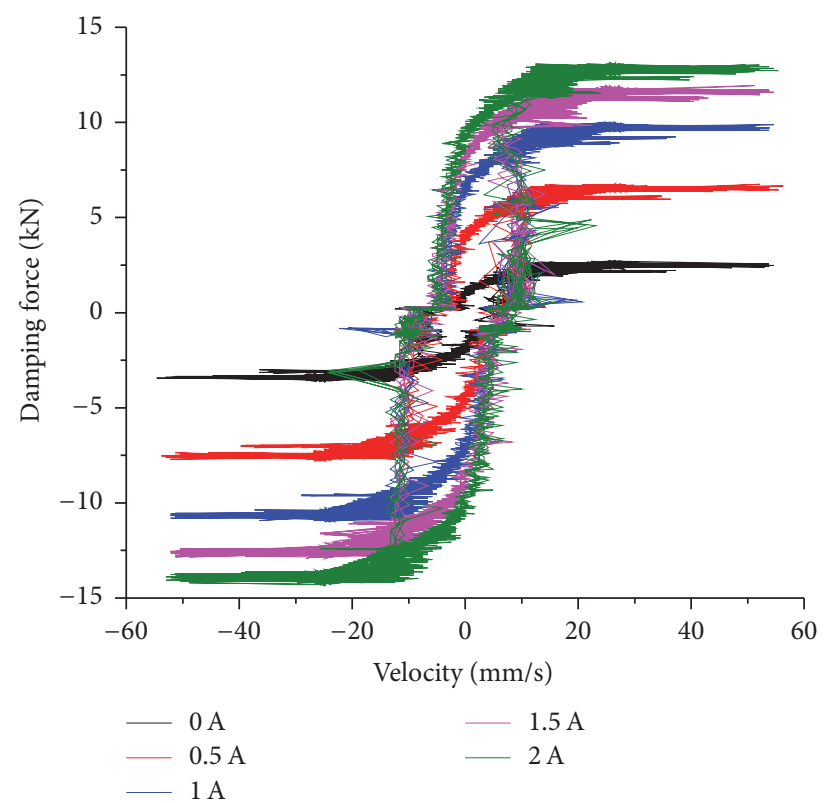

(b) Force-velocity curve

FIGURE 2: Force-displacement and force-velocity hysteresis curves for different currents.

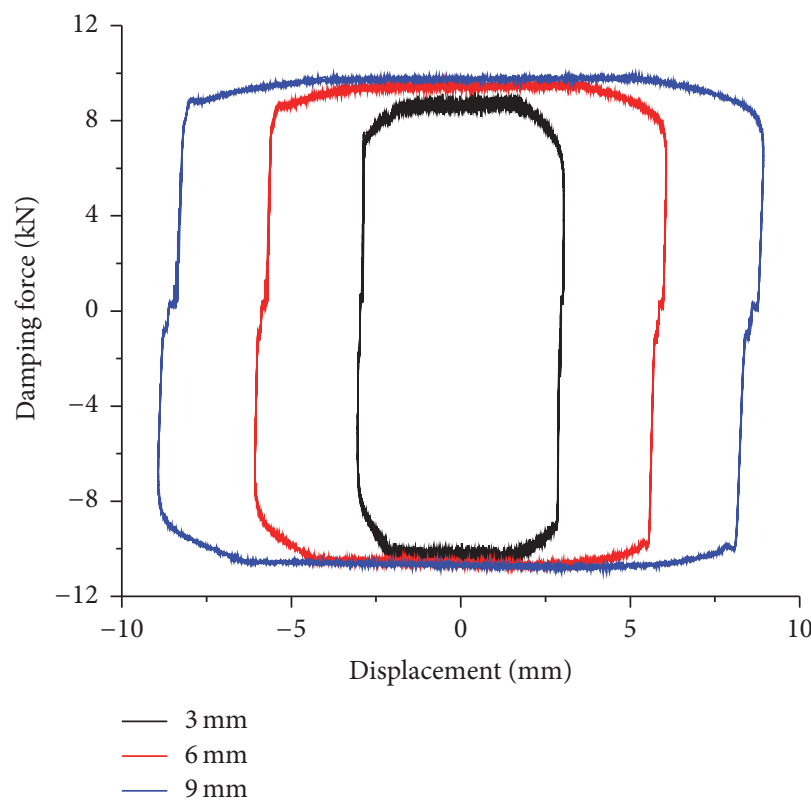

(a) Force-displacement curve

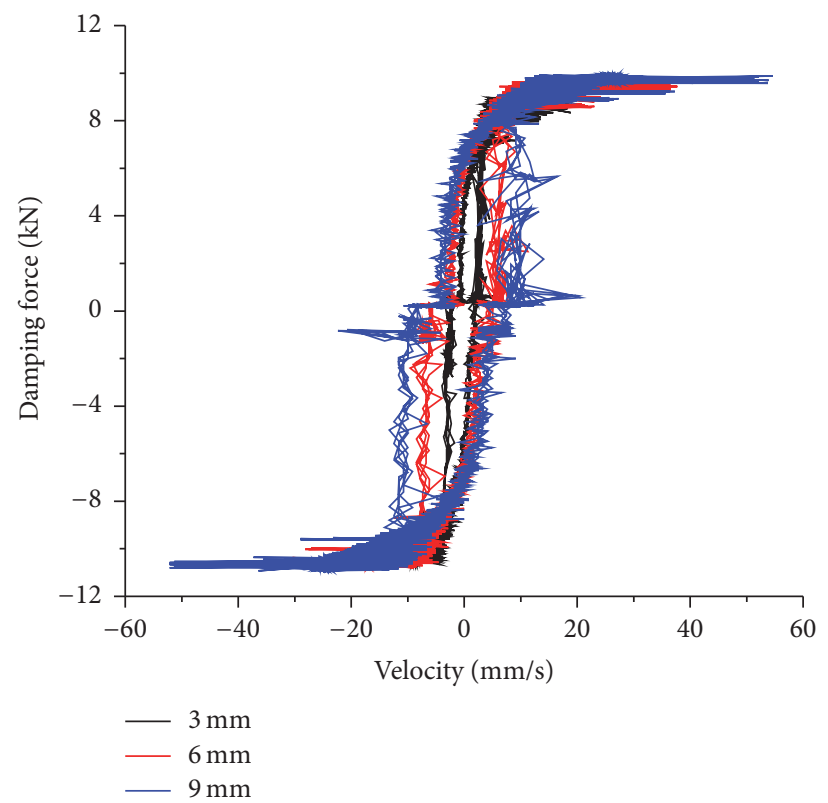

(b) Force-velocity curve

FIgURE 3: Force-displacement and force-velocity hysteresis curves for different amplitudes.

When the input current is $1 \mathrm{~A}$, the loading frequency is $0.5 \mathrm{~Hz}$, and the loading amplitudes are $3 \mathrm{~mm}, 6 \mathrm{~mm}$, and $9 \mathrm{~mm}$, the force-displacement and force-velocity hysteresis curves of the MR damper are shown as Figure 3.

The peak damping force of the MR damper hardly changes as the loading amplitude increases. When the loading amplitudes are $3 \mathrm{~mm}, 6 \mathrm{~mm}$, and $9 \mathrm{~mm}$, the peak damping forces of the MR damper are, respectively, $10.74 \mathrm{kN}, 10.85 \mathrm{kN}$, and $10.92 \mathrm{kN}$.
When the loading amplitude is $9 \mathrm{~mm}$, the input current is $1 \mathrm{~A}$, and the loading frequencies are $0.2 \mathrm{~Hz}, 0.5 \mathrm{~Hz}$, and $1 \mathrm{~Hz}$, the force-displacement and force-velocity hysteresis curves of the MR damper are shown in Figure 4.

The peak damping force of the MR damper changes only slightly as the loading frequency increases. When the loading frequencies are $0.2 \mathrm{~Hz}, 0.5 \mathrm{~Hz}$, and $1 \mathrm{~Hz}$, the peak damping forces of the MR damper are $10.54 \mathrm{kN}, 10.92 \mathrm{kN}$, and $11.53 \mathrm{kN}$, respectively, and the hysteresis loop of the force-velocity curve is greatly affected. 


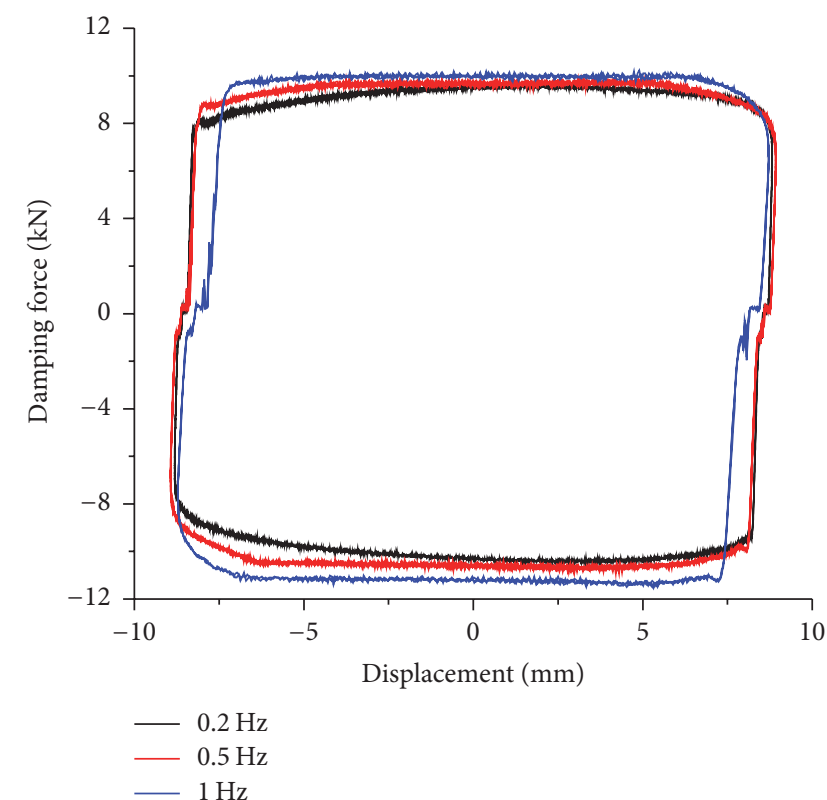

(a) Force-displacement curve

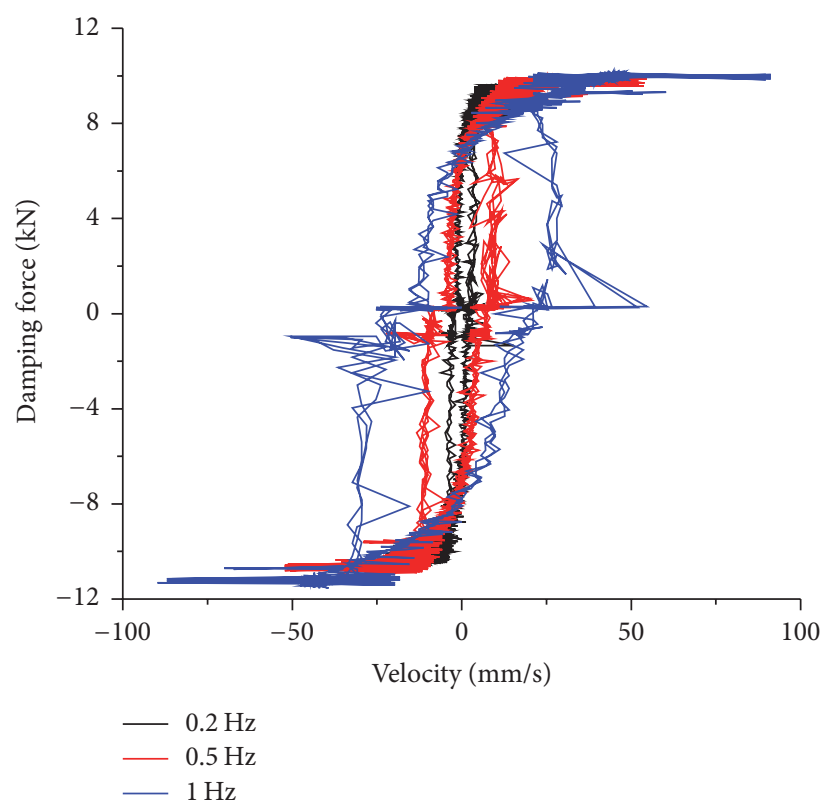

(b) Force-velocity curve

FIGURE 4: Force-displacement and force-velocity hysteresis curves for different frequencies.

\section{Determining the Parameters of the Mechanical Model}

Based on the above experimental results, (2) and (3) can be fit by the least squares method, and the results are $A_{1}=-1895$, $A_{2}=2030 A_{3}=193.5$. Then, the damping force-current relationship can be expressed as

$$
\begin{gathered}
F=\frac{12 \eta L A_{p}^{2}}{\pi D D_{h}^{3}} \dot{u}(t)+\frac{3 L \tau_{y} A_{p}}{D_{h}} \operatorname{sgn}[\dot{u}(t)], \\
\tau_{y}=-1895 e^{-I}+2030 \ln (I+e)+193.5 I .
\end{gathered}
$$

To verify the validity of the model, the model calculation and the experimental result are compared.

When the loading amplitude is $9 \mathrm{~mm}$, the loading frequency is $0.5 \mathrm{~Hz}$, and the input currents are $0 \mathrm{~A}, 0.5 \mathrm{~A}, 1 \mathrm{~A}$, $1.5 \mathrm{~A}$, and $2 \mathrm{~A}$, a comparison between the model calculation and the experimental result is shown in Figure 5.

When the input current is $1 \mathrm{~A}$, the loading frequency is $0.5 \mathrm{~Hz}$, and the loading amplitudes are $3 \mathrm{~mm}, 6 \mathrm{~mm}$, and $9 \mathrm{~mm}$, a comparison between the model calculation and the experimental results is shown in Figure 6.

When the loading amplitude is $9 \mathrm{~mm}$, the input current is $1 \mathrm{~A}$ and the loading frequencies are $0.2 \mathrm{~Hz}, 0.5 \mathrm{~Hz}$, and $1 \mathrm{~Hz}$, a comparison between the model calculation and experimental results is shown in Figure 7.

As seen from Figures 5, 6, and 7, although the damping force-velocity curve of the model calculation cannot describe the hysteresis loop, the trends of the damping force-velocity curve and damping force-displacement curve of the model calculation and the experimental results are approximately the same. This comparison result shows that the fitting of the damping force formula is reasonable.

\section{The Fuzzy Control of the Magnetorheological Damper}

In this paper, the inputs of the fuzzy control are the seismic ground acceleration and the top-layer horizontal displacement, and the output is the input current of the MR damper. According to the basic domain of the inputs and the output and considering the calculation precision and simplicity, their fuzzy domains are, respectively, defined as $0 \sim 4,0 \sim 6$, and $0 \sim 2$. Then, each variable is divided into five levels: \{VS (very small), S (small), M (middle), B (big), and VB (very big)\}.

According to the selection rules of the membership function and the features of the various types of membership function, the membership functions of the seismic acceleration and displacement adopt a nonlinear trapezoidal character that responses sensitively, while that of the MR damper input current adopts a linear triangular form. Figures 8, 9, and 10, respectively, are the input displacement membership function curve, the input seismic acceleration membership function curve, and the output current membership function curve.

In this paper, the value of the control current is small when the seismic acceleration response and the displacement response are small, and its value is large when either the seismic acceleration response or displacement response is large. According to the rules above, a control rule table that consists of 25 fuzzy condition statements is developed as shown in Table 2.

The basic domain of the input and output variables is discretized into five levels: $\{1,2,3,4,5\}$. According to Table 2, which adopts the Mamdani minimax method to perform fuzzy inference and uses a gravity method for the defuzzification, the fuzzy control rule base is produced as shown in Table 3. 


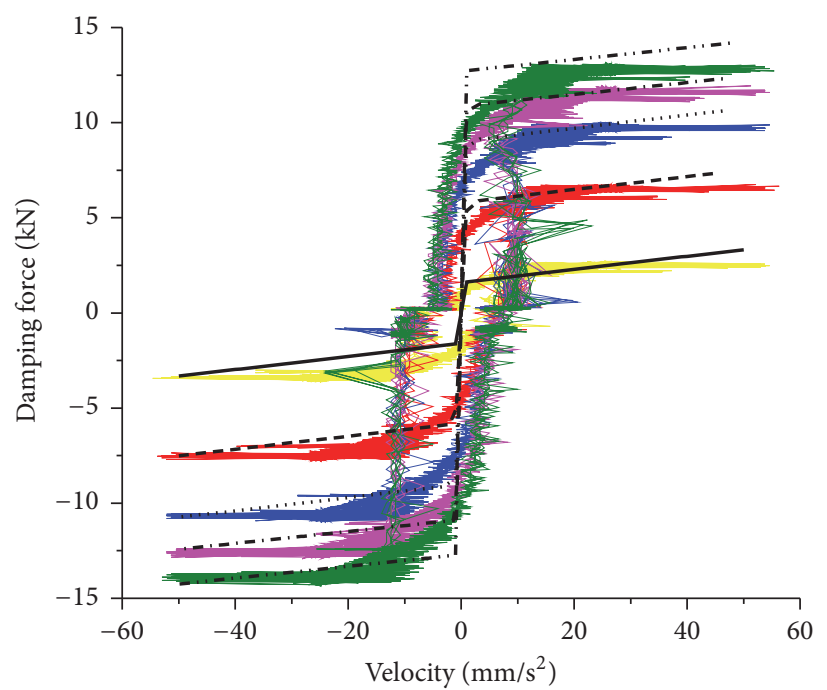

$0 \mathrm{~A}$ experimental result $\quad 0 \mathrm{~A}$ model calculation

- $0.5 \mathrm{~A}$ experimental result $\quad$ - - $-0.5 \mathrm{~A}$ model calculation

- $1 \mathrm{~A}$ experimental result $\quad \ldots . . .1 \mathrm{~A}$ model calculation

- 1.5 A experimental result ...- $1.5 \mathrm{~A}$ model calculation

_ 2 A experimental result $\quad \ldots-2$ A model calculation

(a) Force-velocity curve

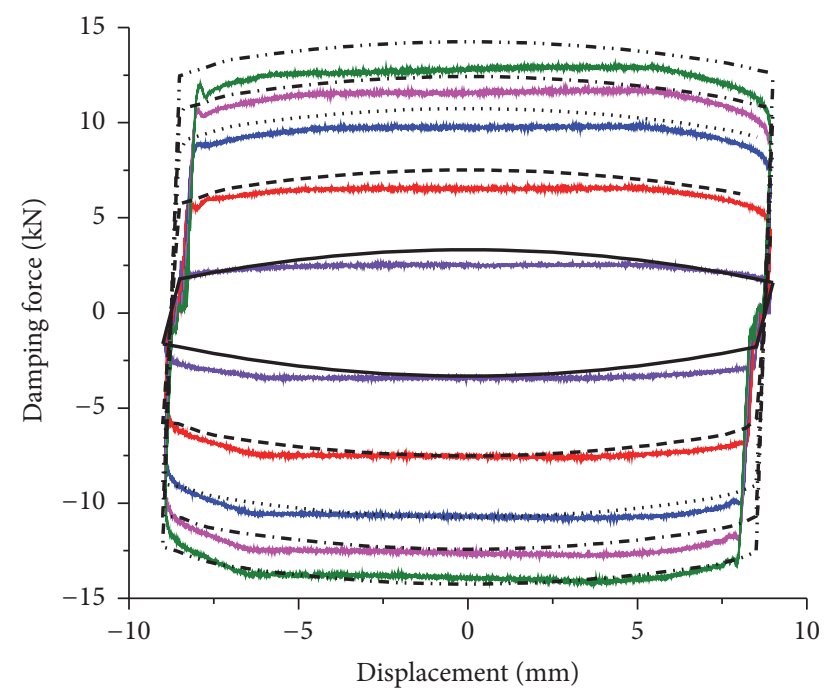

— 0 A experimental result _ _..- 0 A model calculation

— $0.5 \mathrm{~A}$ experimental result _ - - $0.5 \mathrm{~A}$ model calculation

- $1 \mathrm{~A}$ experimental result $\quad \ldots . . .1 \mathrm{~A}$ model calculation

- 1.5 A experimental result _ - - $1.5 \mathrm{~A}$ model calculation

$-2 \mathrm{~A}$ experimental result $\_2 \mathrm{~A}$ model calculation

(b) Force-displacement curve

FIGURE 5: Comparison between model calculation and experimental result for different currents.

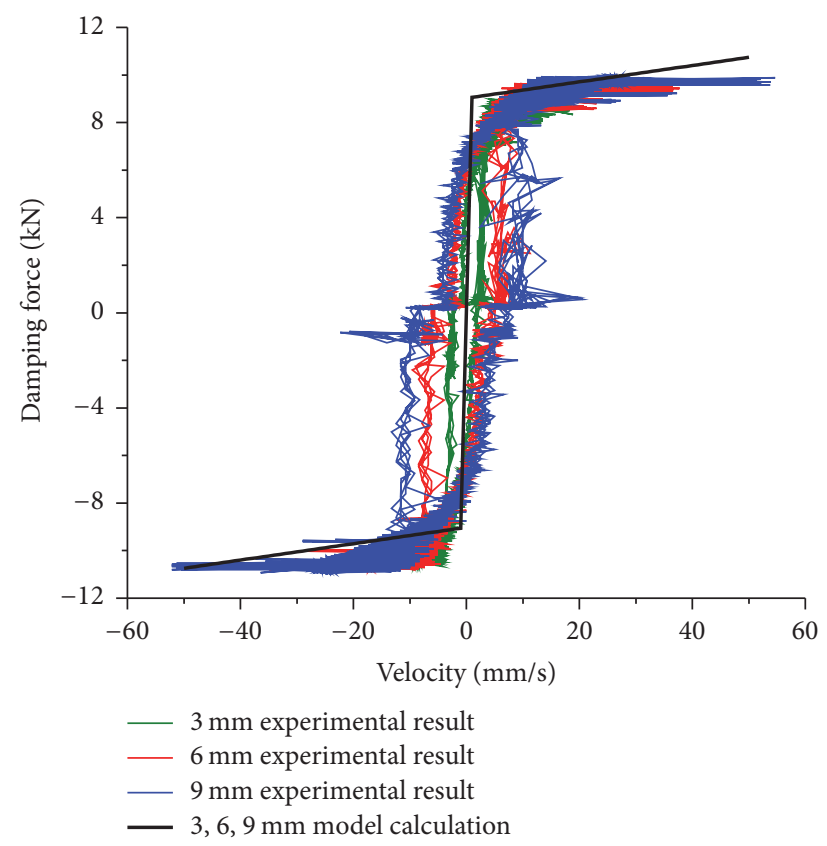

(a) Force-velocity curve

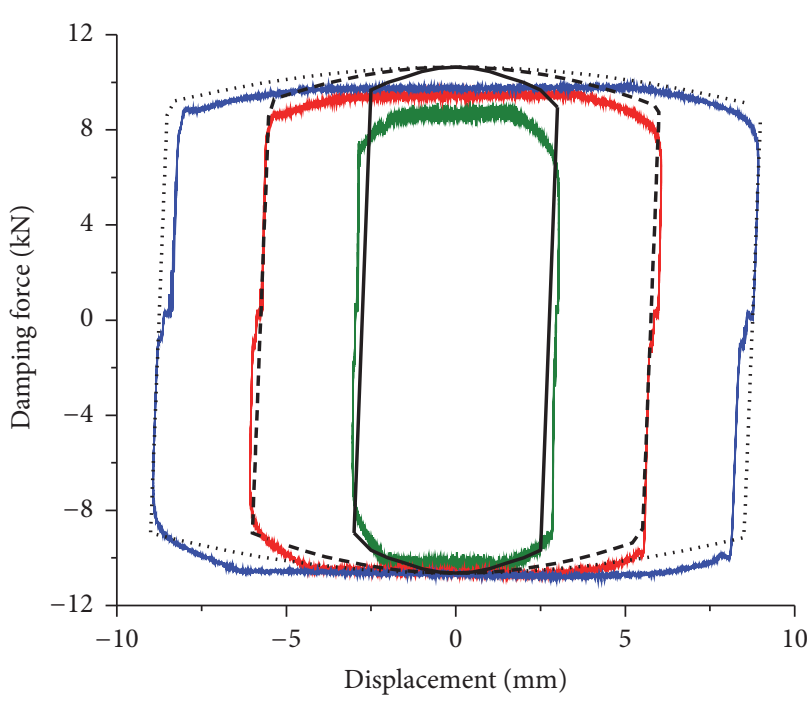

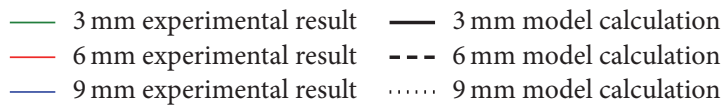

(b) Force-displacement curve

FIGURE 6: Comparison between model calculation and experimental results for different amplitudes.

\section{Optimization of Fuzzy Control}

This paper uses GA and PSO to optimize the fuzzy control rules, respectively, and compares the results with those from modern control theory. The greatest advantage of these optimization algorithms is that choosing the fitness function is easier and the fitness function is not affected by state parameters, so the results are more reliable. The algorithm design is accomplished using MATLAB and Direct Search Toolbox [10]. 

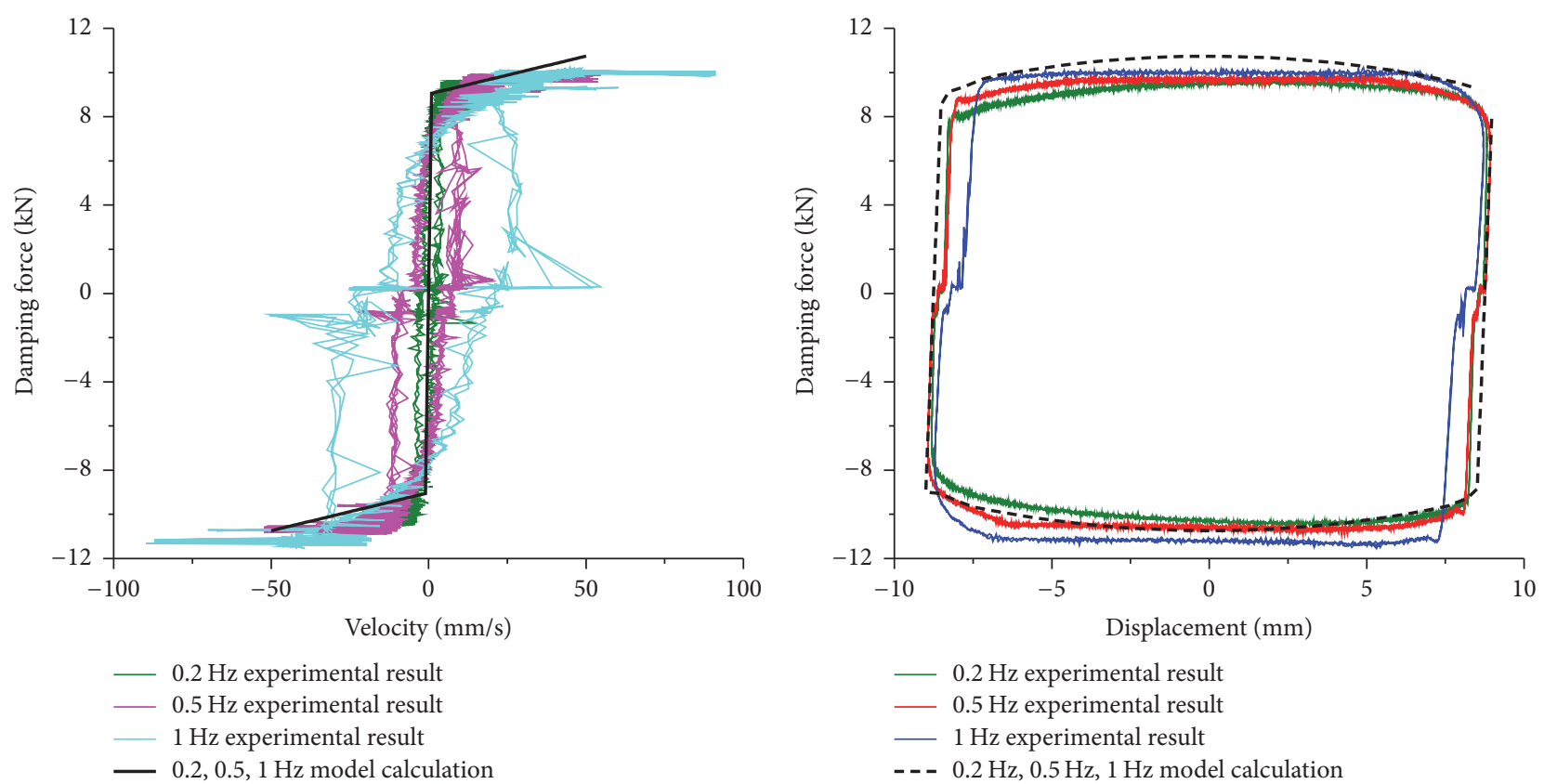

(a) Force-velocity curve

(b) Force-displacement curve

FIGURE 7: Comparison between model calculation and experimental results for different frequencies.

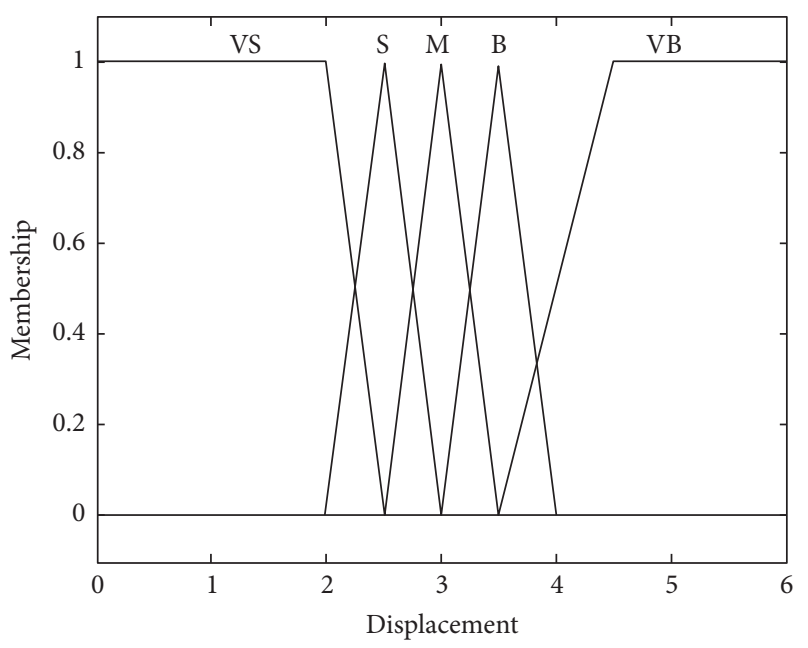

FIgURE 8: Displacement membership function curve.

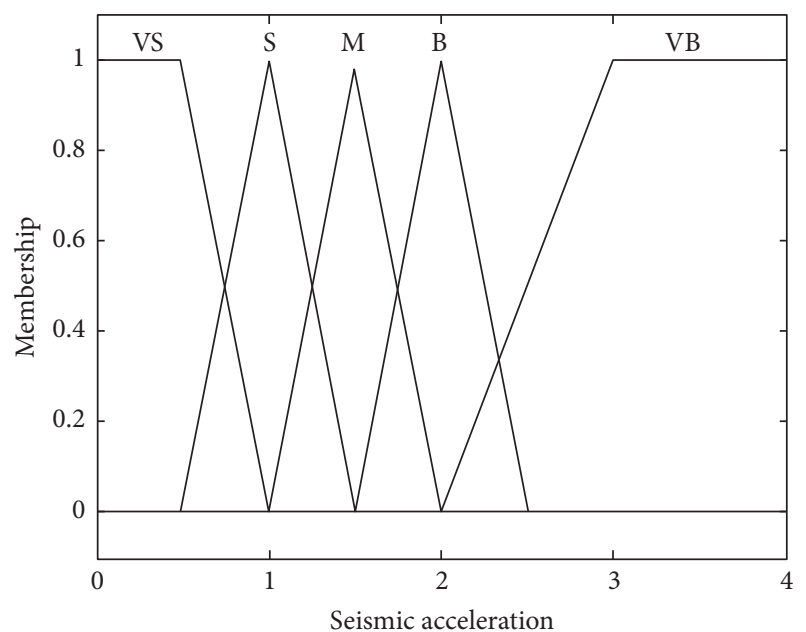

FIGURE 9: Seismic acceleration membership function curve.
TABLE 2: Fuzzy control rule table (current).

\begin{tabular}{lccccc}
\hline \multirow{2}{*}{ Displacement } & \multicolumn{5}{c}{ Seismic acceleration } \\
& VS & S & M & B & VB \\
\hline VS & VS & S & M & B & VB \\
S & S & M & B & B & VB \\
M & M & B & B & VB & VB \\
B & B & B & VB & VB & VB \\
VB & VB & VB & VB & VB & VB \\
\hline
\end{tabular}

TABLE 3: Fuzzy control rule table (current).

\begin{tabular}{llllll}
\hline \multirow{2}{*}{ Displacement } & \multicolumn{5}{c}{ Seismic acceleration } \\
& 1 & 2 & 3 & 4 & 5 \\
\hline 1 & 1 & 2 & 3 & 4 & 5 \\
2 & 2 & 3 & 4 & 4 & 5 \\
3 & 3 & 4 & 4 & 5 & 5 \\
4 & 4 & 4 & 5 & 5 & 5 \\
5 & 5 & 5 & 5 & 5 & 5 \\
\hline
\end{tabular}




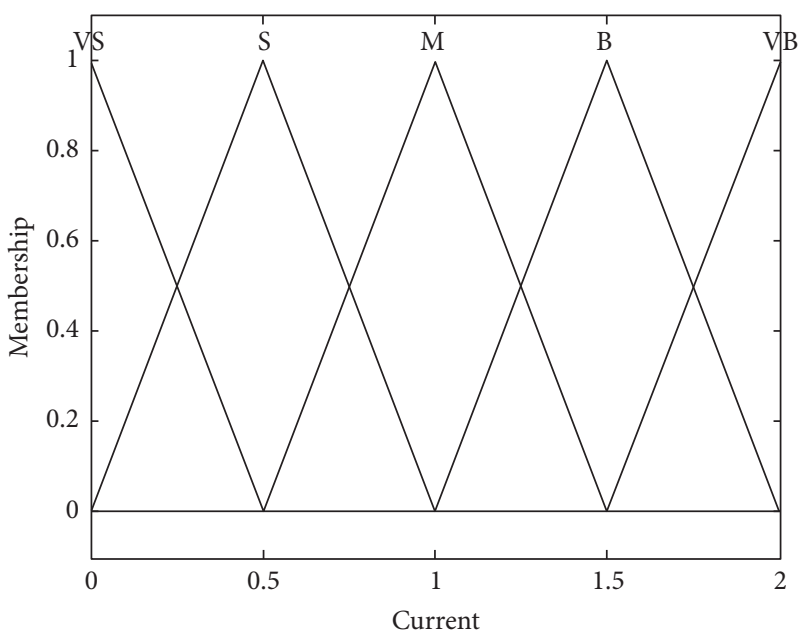

FIGURE 10: Current membership function curve.

\subsection{Fuzzy Control Optimized by GA}

(1) Coding Scheme. The fuzzy control rule base contains a total of 25 elements. The 25 elements are sequenced into a list of numbers from left to right and top to bottom, and these numbers represent individuals in the population. This paper uses binary encoding to improve the algorithm running speed, so each element can be represented as $001 \ldots 011 \ldots 100 \ldots$, and the whole rule base can thus be represented by 75 characters. According to the setting of the output discretization, the value range of every output number is limited to $1 \sim 5$.

(2) Setting of the Initial Population. According to the binary encoding rules, a certain number of individuals are randomly generated, and then the best individual is picked to join the initial population. Iterations are performed constantly in this manner until the size of the initial population has reached the preset.

(3) Selection of the Fitness Function. A genetic algorithm usually carries out genetic manipulation according to a fitness function that is selected by the control target. The final target of the designed control strategies in the paper for the MR damper is to effectively reduce the structure displacement and acceleration response. The control target of the genetic algorithm is the peak value of the displacement acceleration response peak value. The fitness function of the displacement response peak can be expressed as

$$
\Phi_{1}=\max _{t}\left(\frac{|x(t)|}{x_{\text {unc }}(t)}\right) .
$$

In (5), $x(t)$ represents the displacement response of the structure layer $t$ and $x_{\text {unc }}(t)$ represents the maximum displacement response of the uncontrolled structure.

$$
\Phi_{2}=\max _{t}\left(\frac{|\ddot{x}(t)|}{\ddot{x}_{\text {unc }}(t)}\right) .
$$

In (6), $\ddot{x}(t)$ represents the acceleration response of the structure layer $t$ and $\ddot{x}_{\text {unc }}(t)$ represents the maximum acceleration response of the uncontrolled structure.

To simplify, this paper chooses (7) as the fitness function of the genetic algorithm.

$$
\Phi=\Phi_{1}+\Phi_{2} .
$$

In (7), $\Phi_{1}$ represents the peak value of the structural relative displacement response and $\Phi_{2}$ represents the peak value of the structural relative acceleration response.

(4) Genetic Manipulation. The genetic manipulation of the genetic algorithm includes selection, crossover, and mutation.

The selection of the operators adopts the stochastic uniform method based on the layout of a straight line, where each parent, individual, occupies a part of the line in proportion to its fitness value. The algorithm moves along the line using a uniform step size, and in each step, the algorithm verifies an individual's parents according to the position of the stop.

The dispersion crossover function is selected as the crossover function. The operator creates a binary encoding vector whose length is equal to the length of the individual binary encoding. If a certain position in this vector has a value of 1 , the corresponding position gene of the offspring individual is from its first parent; otherwise, the gene is from its second parent.

An adaptive function that randomly generates a mutation direction and quantity for each individual gene according to its individual fitness value is selected as the variation function. The genetic variance is limited in the range of the set of the genetic algorithm.

The flow chart of the fuzzy control optimized by GA is shown in Figure 11.

\subsection{Fuzzy Control Optimized by PSO}

(1) Coding Scheme. The fuzzy control rule base is a $5 \times 5$ real matrix, as shown in Table 3 . The coding uses real number coding. The 25 elements in the matrix are sorted into a one-dimensional vector that can be regarded as a particle. Hypothetically, line $i$ of the matrix element is $a_{i j}$, so the coding for the particles is

$$
a_{1 j}, a_{2 j}, a_{3 j}, a_{4 j}, a_{5 j} \quad(j=1,2, \ldots, 5) .
$$

(2) Setting of the Initial Population. To achieve the control purpose of the initial population and enable a more meaningful evaluation in the process of evolution, this paper adds a random real number between $[-c, c]$ to each element of the binary encoding that is based on Table 3 , and then the initial population is generated. Iterations are done continuously in this way until the optimum solution is identified. The value of $c$ directly affects the searching ability of the algorithm. A larger $c$ is helpful to improve the global searching ability of the algorithm, but a smaller $c$ is helpful to improve the local searching ability. The value of $c$ in this paper refers to the 


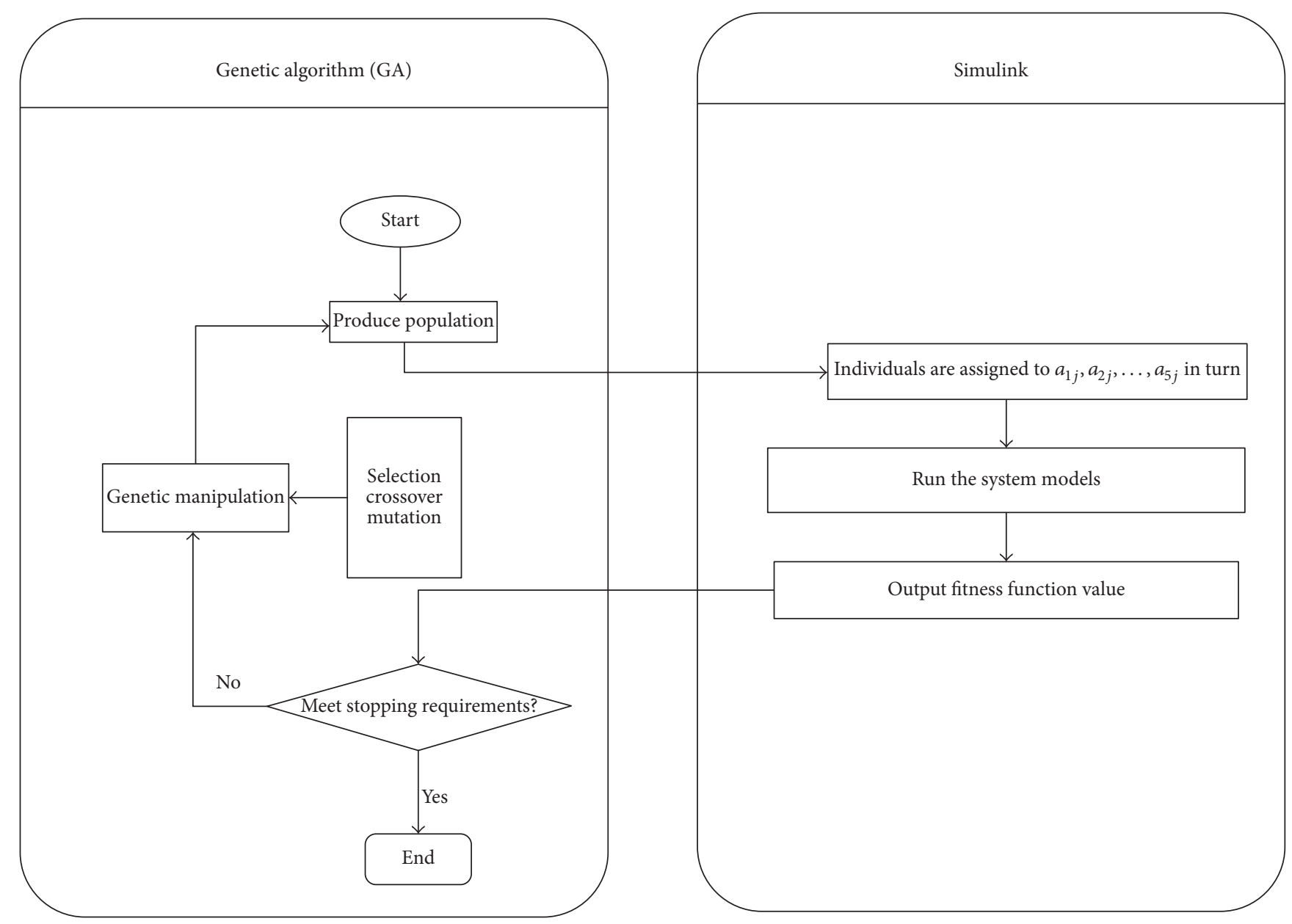

Figure 11: Flow chart of the fuzzy control optimized by GA.

maximal element $\left(a_{i j}\right)_{\max }$ in Table 2, shown as

$$
c<\left(a_{i j}\right)_{\max } \quad(i=1,2, \ldots, 5 ; j=1,2, \ldots, 5) .
$$

(3) Memory Database. The memory database that is used to store the optimal particles in the process of evolution performs iteration according to

$$
\begin{aligned}
v_{d}= & \omega v_{d}+c_{1} * r_{1} *\left(\text { pbest }_{d}-x_{d}\right)+c_{2} * r_{2} \\
& *\left(\text { gbest }_{g d}-x_{d}\right) \\
x_{d+1}= & x_{d}+v_{d+1} .
\end{aligned}
$$

In (10), $\omega$ is the inertia weight, whose size determines the current speed that the particles inherit; $c_{1}$ and $c_{2}$ are learning factors, usually $c_{1}, c_{2} \in[0,4] ; r_{1}$ and $r_{2}$ are random numbers between $[0,1]$; pbest $t_{d}$ is the coordinates of the $d$ thdimension individual extremum of the particle; and $g b e s t_{g d}$ are the coordinates of the $d$ th-dimension global extremum of the population.

(4) Selection of Fitness Function. The final target of the designed control strategies in the paper for the MR damper is effectively reducing the structure displacement and acceleration response, so the displacement and acceleration are chosen to evaluate the individual performance. The fitness functions still use (5), (6), and (7).

(5) Process of Optimization Design. The bridge between particle swarm optimization and the Simulink model is the particle (fuzzy control rules) and the fitness of the particle (performance of the control system).

Particle swarm optimization generates a particle swarm whose particles are assigned in a sequence according to fuzzy control rules $a_{1 j}, a_{2 j}, a_{3 j}, a_{4 j}$, and $a_{5 j}(j=1,2, \ldots, 5)$ and then the performances in correspondence with this group of parameters are obtained from operating the Simulink model. The performances are transmitted to the particle swarm optimization as fitness, ultimately judging whether or not to exit the program.

The flow chart of the fuzzy control optimized by PSO is shown in Figure 12.

Both FGA and FPSO enhance the control effects by optimizing fuzzy control rules, but the fuzzy control rules of the two control strategies are different for the same building. Meanwhile, for different building structures, the two control 


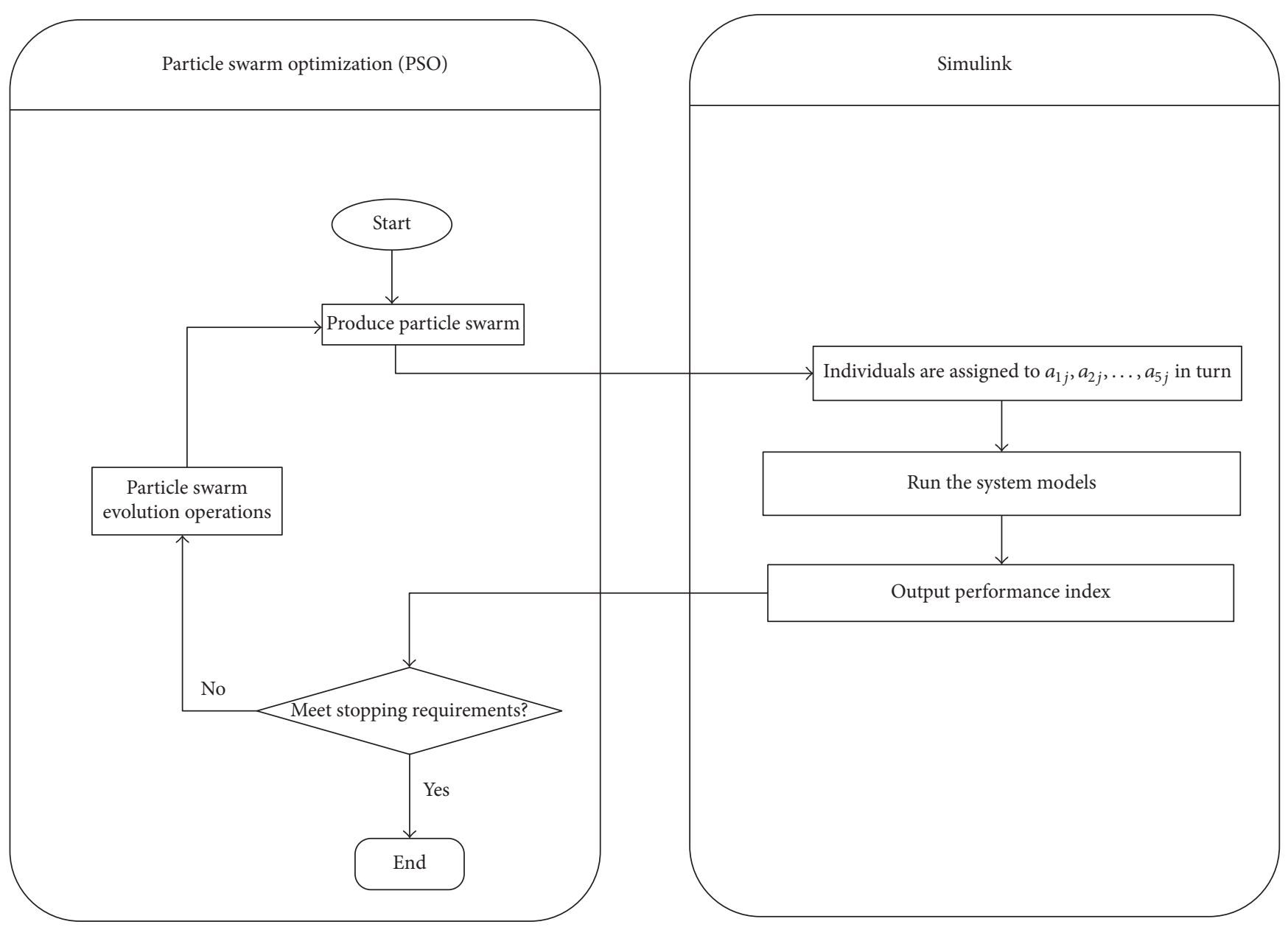

FIGURE 12: Flow chart of the fuzzy control optimized by PSO.

strategies will generates different and proper fuzzy control rules which have no reference to the loads of seismic waves.

\section{An Example Analysis of the Magnetorheological Damping Structure}

Consider a three-layer reinforced concrete frame structure with a hypothetical seismic fortification intensity of 8 degrees, a type of site of type II, masses of each layer of $m_{1}=20310 \mathrm{~kg}$, $m_{2}=18980 \mathrm{~kg}$, and $m_{3}=16950 \mathrm{~kg}$, stiffness of each layer of $k_{1}=1.536 \times 10^{7} \mathrm{~N} / \mathrm{m}, k_{2}=2.018 \times 10^{7} \mathrm{~N} / \mathrm{m}$, and $k_{3}=2.018 \times 10^{7} \mathrm{~N} / \mathrm{m}$, and heights of each layer of $h_{1}=4 \mathrm{~m}$, $h_{2}=3.3 \mathrm{~m}$, and $h_{3}=3.3 \mathrm{~m}$. Each layer of the structure is set as an MR damper.

This paper performs a numerical simulation [10] for the structure under the conditions of the uncontrolled structure (UNC), fuzzy control (F), fuzzy control optimized by GA (FGA), and fuzzy control optimized by PSO (FPSO). Then, the simulation consequence is compared with that of GAoptimized FLC control (GA-FLC) proposed by Ali and Ramaswamy [7] to verify the effectiveness of FGA and FPSO. GA-FLC uses a restart genetic algorithm-based optimization strategy to promote the fuzzy system properties like the fuzzy rule base, prescale gains, membership function type, and parameters at every simulation step [7].

To reflect the real working state of the reinforced concrete structure in the elastoplastic region under cyclic loading, the stiffness degradation model of reinforced concrete suggested by Clough is used to analyse the elastoplastic deformation of the structure. Two natural seismic waves $\{\mathrm{El}$ Centro wave $(1940$, NS) and Taft wave $\}$ and an artificial seismic wave (Nanjing wave) whose peaks are all adjusted to $400 \mathrm{~mm} / \mathrm{s}^{2}$ were chosen, so that the domain of the seismic acceleration may be determined as $0 \sim 0.4 \mathrm{~m} / \mathrm{s}^{2}$. For the controlled structure, the basic domain of the structure displacement response is $0 \sim h / 200$ under a basic fortification intensity, where $h$ is the layer height. The duration and time step are set to $15 \mathrm{~s}$ and $0.02 \mathrm{~s}$, respectively.

The flow chart of the structure simulation program under seismic action is shown as Figure 13.

The initial population size of the genetic algorithm is set to 100 , the genetic generations is 100 , and the crossover probability is 0.6 . The parameters of the particle swarm optimization are an inertial multiplier of $\omega=0.6$, an 


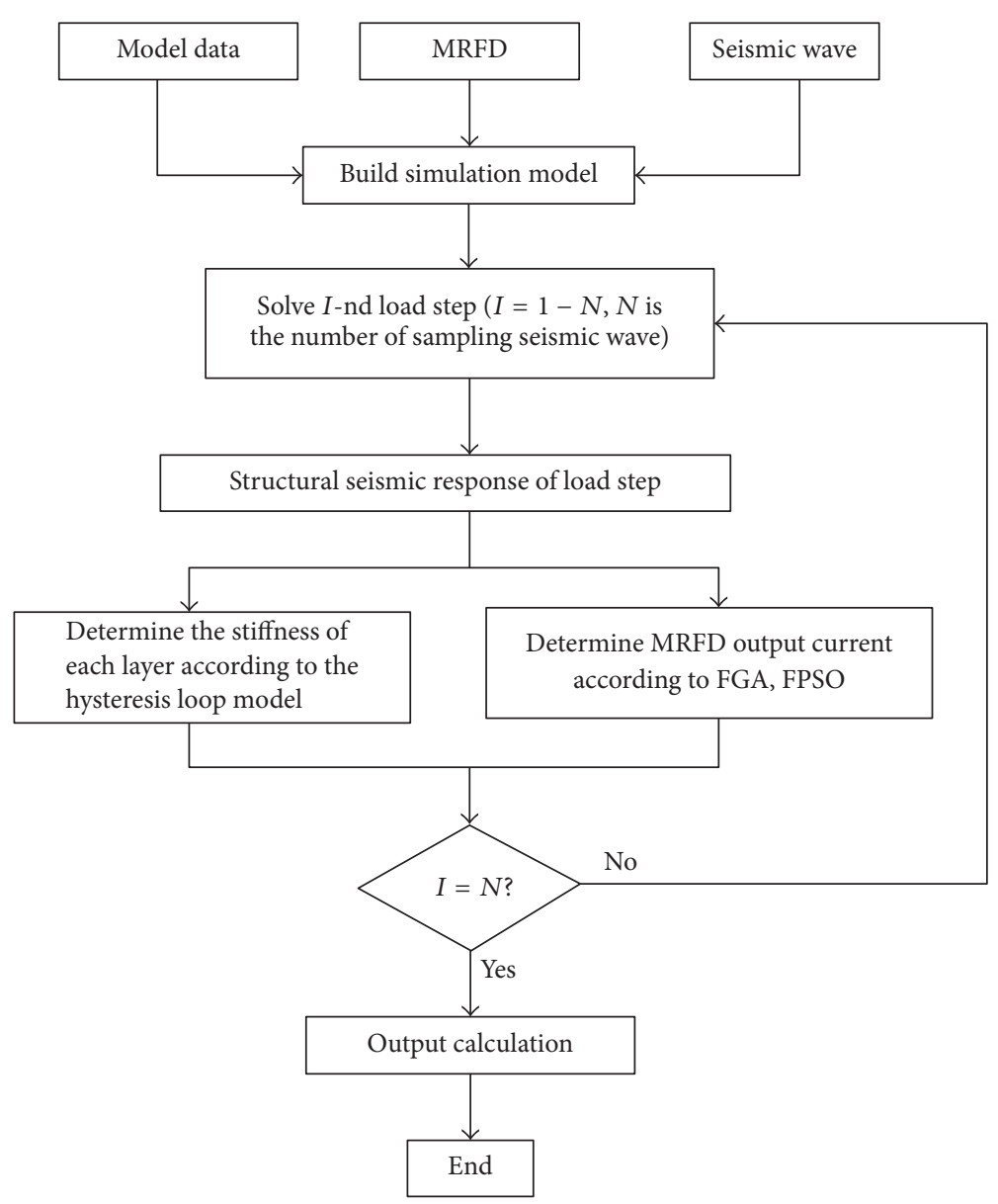

FIGURE 13: Flow chart of structure simulation program under seismic action.

TABLE 4: Fuzzy control rule table of fuzzy control optimized by GA (current).

\begin{tabular}{lccccc}
\hline \multirow{2}{*}{ Displacement } & \multicolumn{5}{c}{ Seismic acceleration } \\
& 1 & 2 & 3 & 4 & 5 \\
\hline 1 & 3 & 4 & 1.87 & 3.27 & 3.78 \\
2 & 3.74 & 2.38 & 3.17 & 2.37 & 2.98 \\
3 & 2.98 & 3.78 & 4.17 & 4.67 & 4.01 \\
4 & 4.75 & 4.96 & 2.87 & 5 & 5 \\
5 & 5 & 4.21 & 3.58 & 5 & 5 \\
\hline
\end{tabular}

acceleration constant $c 1=c 2=2$, a real number $c=5$, a particle swarm size of 100, a maximal number of iterations of 100 , and the range of the optimizing parameters is $[1,5]$. The two types of optimization algorithm both choose (5) as the fitness function. Running the program above can obtain the fuzzy control rule base of fuzzy control optimized by GA and the fuzzy control rule base of fuzzy control optimized by PSO, shown in Tables 4 and 5, respectively.

Figure 14 expresses the convergence circumstance of the FGA and FPSO optimization algorithms, and Table 6 shows the program running time and the fitness of these two
TABLE 5: Fuzzy control rule table of fuzzy control optimized by PSO (current).

\begin{tabular}{lccccc}
\hline \multirow{2}{*}{ Displacement } & \multicolumn{5}{c}{ Seismic acceleration } \\
& 1 & 2 & 3 & 4 & 5 \\
\hline 1 & 2.5 & 3.6 & 1.2 & 4.6 & 3.3 \\
2 & 2.3 & 3.1 & 3.3 & 2.2 & 4.0 \\
3 & 3.5 & 3.1 & 2.7 & 3.3 & 4.6 \\
4 & 3.7 & 2.3 & 5.0 & 4.7 & 3.4 \\
5 & 4.0 & 4.5 & 3.9 & 5.0 & 5.0 \\
\hline
\end{tabular}

TABLE 6: Running time and fitness of the two optimization algorithms.

\begin{tabular}{lcc}
\hline Control conditions & Running time $(\mathrm{s})$ & Fitness value \\
\hline FGA & $37.308 \times 10^{3}$ & 1.687801 \\
FPSO & $45.015 \times 10^{3}$ & 1.679326 \\
\hline
\end{tabular}

optimization algorithms. As shown in Figure 12 and Table 6, the convergence fitness of these two optimization algorithms is close (FGA: 1.687801; FPSO: 1.679326), but the speed of 


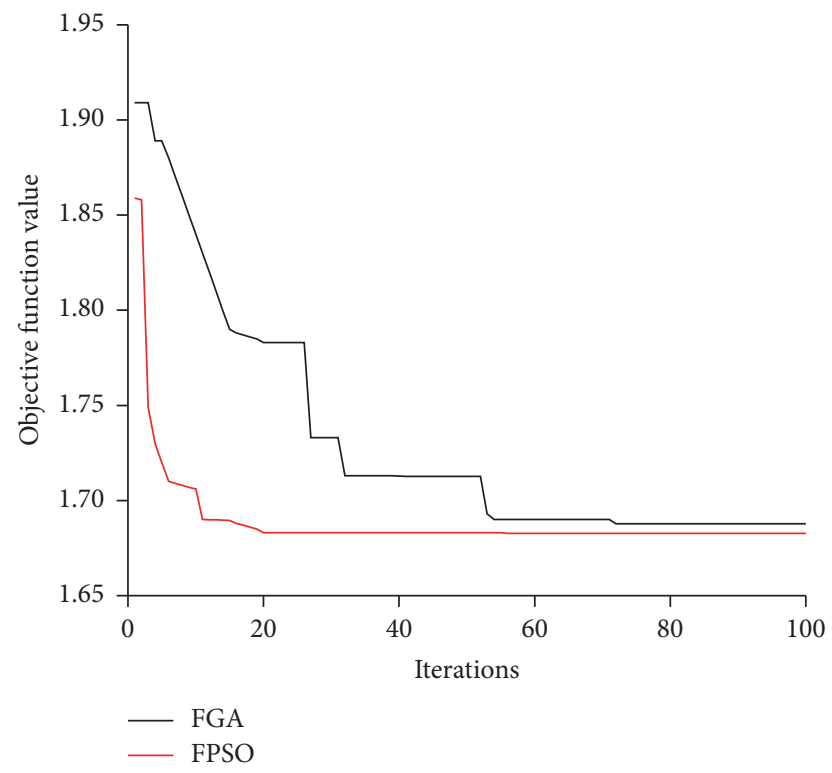

Figure 14: Convergence situation of the two optimization algorithms.

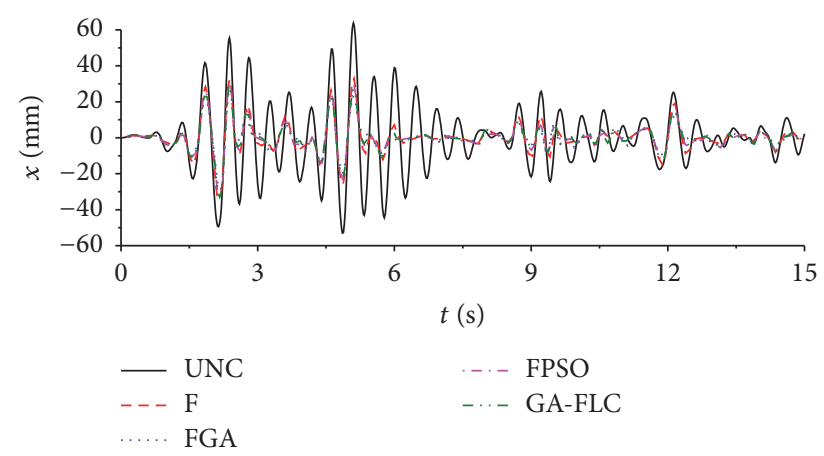

FIgURE 15: Top-layer displacement response curve under the action of the El Centro wave.

convergence of the fuzzy control optimized by PSO is significantly faster, while the running time of FGA is clearly shorter (FGA: $37.308 \times 10^{3} \mathrm{~s}$; FPSO: $45.015 \times 10^{3} \mathrm{~s}$ ). Therefore, when the program running time is limited or when optimizing huge building structures, FGA should be better than FPSO.

Figures 15, 16, and 17 are the top-layer displacement response curve of the uncontrolled structure (UNC), fuzzy control (F), fuzzy control optimized by GA (FGA), fuzzy control optimized by PSO (FPSO), and GA-optimized FLC control (GA-FLC) under the action of the El Centro wave, Taft wave, and Nanjing wave, respectively. Figures 18, 19, and 20 are the top-layer acceleration response curves of UNC, F, FGA, FPSO, and GA-FLC under the action of the El Centro wave, Taft wave, and Nanjing wave, respectively. As shown in the figure, upon comparing the displacement and acceleration of the structure, the effects of fuzzy control optimized by GA, fuzzy control optimized by PSO, and GA-optimized FLC control (GA-FLC) are much better than that of human experience fuzzy control. For the control of displacement, the effects of FGA and FPSO are similar to that

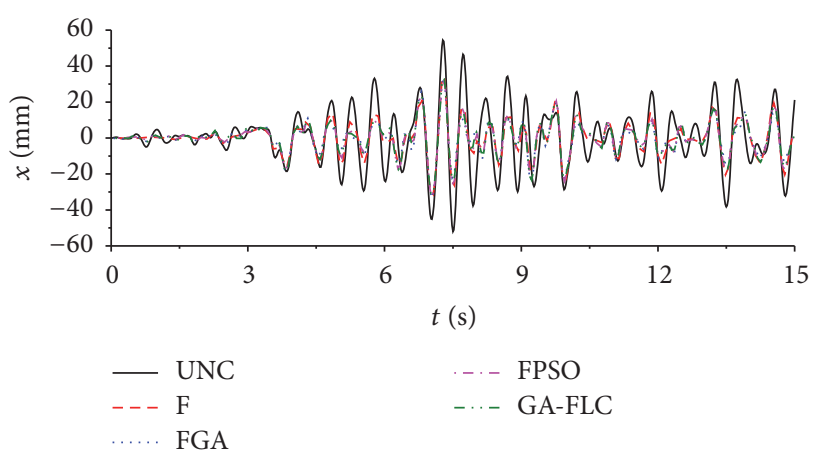

FIGURE 16: Top-layer displacement response curve under the action of the Taft wave.

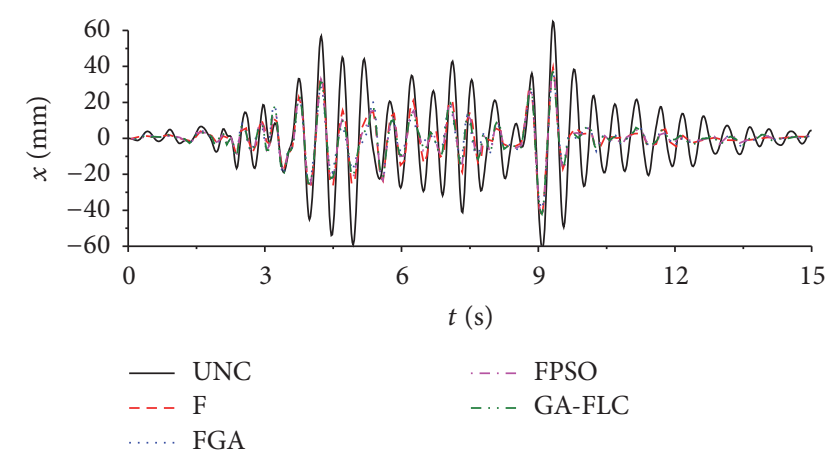

FIGURE 17: Top-layer displacement response curve under the action of the Nanjing wave.

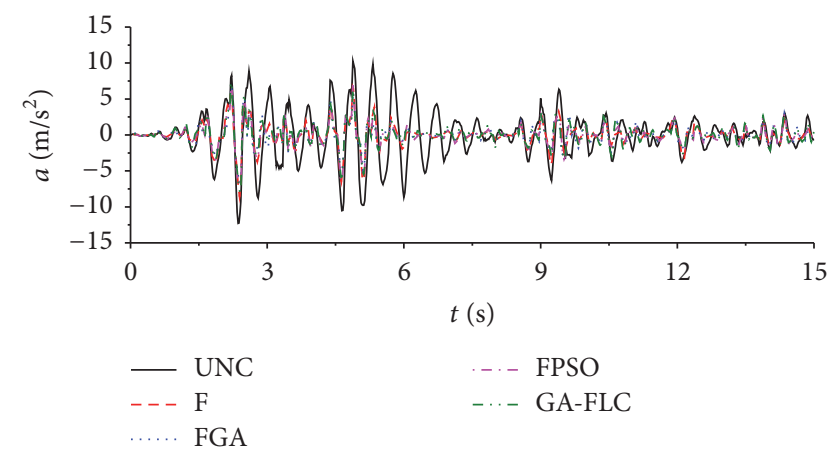

FIGURE 18: Top-layer acceleration response curve under the action of the El Centro wave.

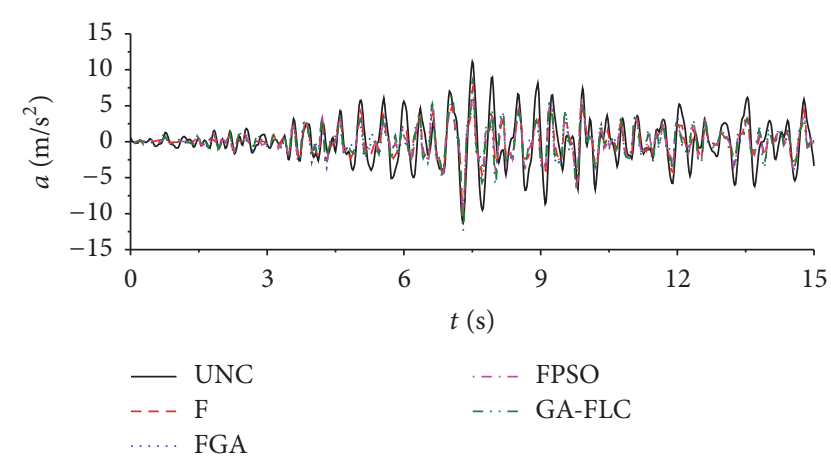

Figure 19: Top-layer acceleration response curve under the action of the Taft wave. 


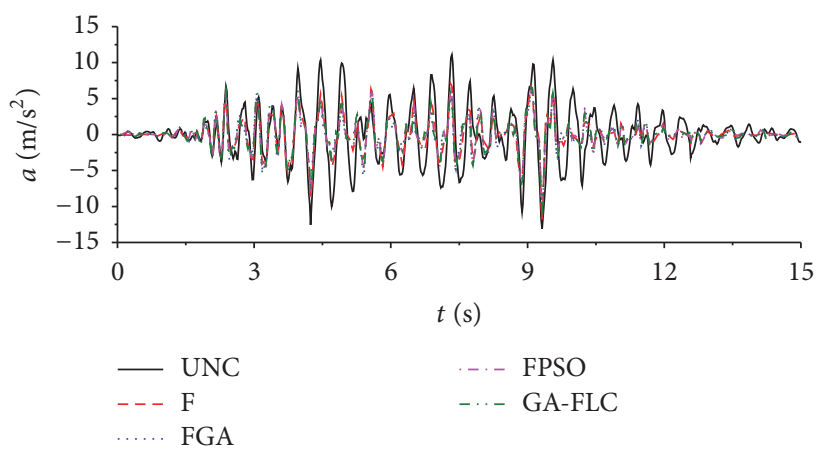

FIGURE 20: Top-layer acceleration response curve under the action of the Nanjing wave.
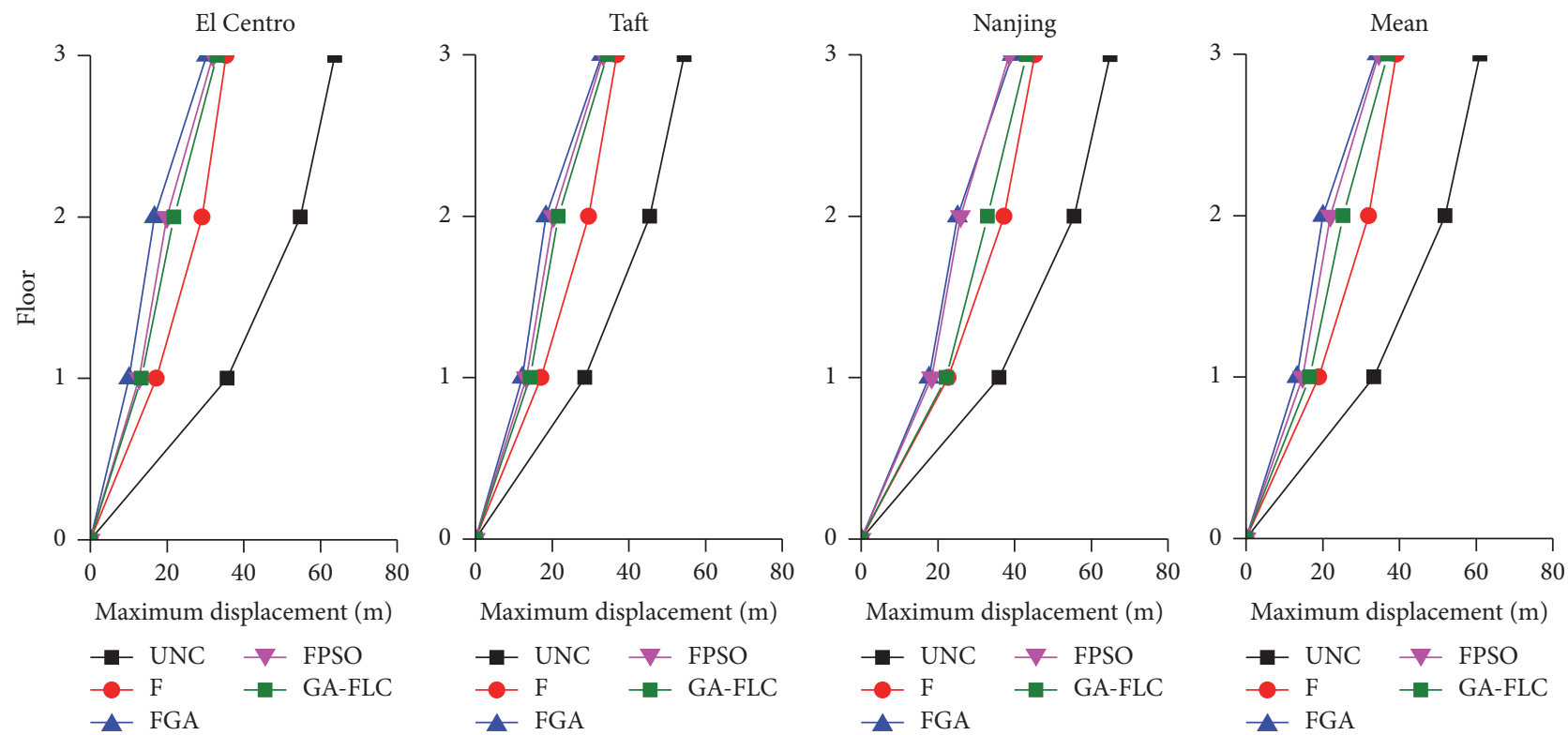

FIGURE 21: Each layer's displacement response peak under the action of three seismic waves.

of GA-FLC. Meanwhile, for the control of acceleration, the effects of FGA and FPSO are superior to that of GA-FLC.

Table 7 lists each layer's peak displacement and peak acceleration under the actions of the three types of seismic wave, together with the average values for all three waves. As shown in the table, the damping effects of the two optimized fuzzy controls are clearly better than those of the fuzzy control and close to those of the GA-FLC.

In Table 7, $J_{1}=\left(\max \left|x_{c}(t)\right| / \max \left|x_{\text {unc }}(t)\right|\right) \times 100 \% ; J_{2}=$ $\left(\max \left|\ddot{x}_{c}(t)\right| / \max \left|\ddot{x}_{\text {unc }}(t)\right|\right) \times 100 \% . x_{c}(t), \ddot{x}_{c}(t)$ represent the structure displacement and acceleration response under the action of control, while $x_{\text {unc }}(t), \ddot{x}_{\text {unc }}(t)$ represent the structure displacement and acceleration response without control.

Figure 21 expresses each structural layer's peak displacement and the average peak displacement in the five control conditions under the action of the El Centro wave, Taft wave, and Nanjing wave. Figure 22 expresses each structural layer's peak acceleration and the average peak acceleration in the five control conditions under the action of the El Centro wave, Taft wave, and Nanjing wave. The figures show that the optimized fuzzy controls reduce each layer's peak displacement and acceleration, and the average peak displacement and acceleration of the three seismic waves are more efficient than those under human experience fuzzy control.

\section{Conclusion}

(1) This paper proposes new fuzzy control rules based on the genetic algorithm (GA) and particle swarm optimization (PSO) and performs a numerical simulation on a threelayer reinforced concrete frame structure under conditions of an uncontrolled structure, fuzzy control, fuzzy control optimized by GA, and fuzzy control optimized by PSO. The control effect is great.

(2) Analysing the convergence process and program running time, the convergence fitness values of these two optimization algorithms are close (FGA: 1.687801; FPSO: 1.679326), but the convergence speed of the fuzzy control 

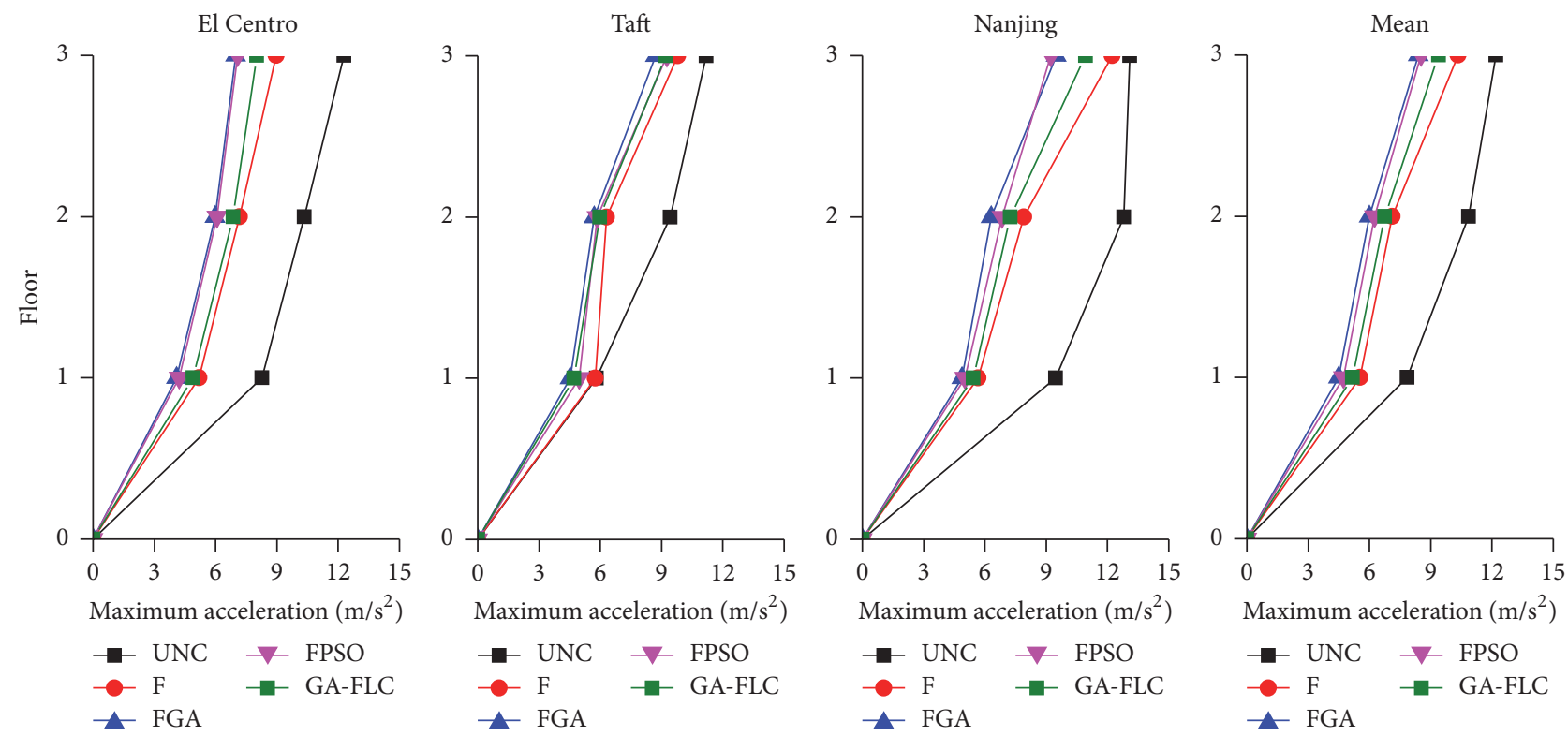

FIGURE 22: Each layer's acceleration response peak under the action of three seismic waves.

TABLE 7: Each layer's peak displacement and acceleration control effect under the three types of seismic wave.

\begin{tabular}{|c|c|c|c|c|c|c|c|}
\hline \multirow{2}{*}{\multicolumn{2}{|c|}{$\begin{array}{c}\text { Evaluation index } \\
\text { Floor }\end{array}$}} & \multicolumn{3}{|c|}{$J_{1}$} & \multicolumn{3}{|c|}{$J_{2}$} \\
\hline & & 1 & 2 & 3 & 1 & 2 & 3 \\
\hline \multirow{4}{*}{ El Centro wave } & $\mathrm{F}$ & 51.86 & 46.73 & 44.37 & 37.29 & 30.72 & 27.02 \\
\hline & FGA & 71.77 & 69.41 & 52.44 & 50.62 & 42.22 & 43.18 \\
\hline & FPSO & 64.27 & 63.54 & 49.80 & 30.72 & 41.33 & 42.35 \\
\hline & GA-FLC & 62.78 & 60.22 & 48.06 & 40.82 & 33.76 & 34.82 \\
\hline \multirow{4}{*}{ Taft wave } & $\mathrm{F}$ & 39.93 & 35.13 & 32.22 & 9.30 & 33.10 & 12.39 \\
\hline & FGA & 57.33 & 59.49 & 39.48 & 22.00 & 39.57 & 22.14 \\
\hline & FPSO & 53.30 & 55.18 & 38.77 & 14.37 & 37.90 & 17.21 \\
\hline & GA-FLC & 49.92 & 52.49 & 36.80 & 18.82 & 36.58 & 17.64 \\
\hline \multirow{4}{*}{ Nanjing wave } & $\mathrm{F}$ & 37.01 & 33.02 & 30.30 & 40.03 & 38.28 & 6.55 \\
\hline & FGA & 50.85 & 54.83 & 39.37 & 48.53 & 50.76 & 27.50 \\
\hline & FPSO & 48.92 & 53.32 & 40.59 & 46.85 & 46.62 & 29.55 \\
\hline & GA-FLC & 38.26 & 40.72 & 33.63 & 42.72 & 43.31 & 16.51 \\
\hline \multirow{4}{*}{ Average value } & $\mathrm{F}$ & 43.13 & 38.44 & 35.77 & 29.43 & 46.62 & 15.22 \\
\hline & FGA & 60.14 & 61.31 & 43.95 & 42.80 & 44.83 & 31.13 \\
\hline & FPSO & 55.65 & 57.62 & 43.25 & 39.62 & 42.43 & 30.08 \\
\hline & GA-FLC & 50.32 & 51.14 & 39.50 & 34.12 & 37.88 & 22.99 \\
\hline
\end{tabular}

optimized by PSO is clearly faster than that of the fuzzy control optimized by GA; in addition, the running time of FGA is clearly shorter than that of FPSO (FGA: $37.308 \times 10^{3} \mathrm{~s}$; FPSO: $45.015 \times 10^{3} \mathrm{~s}$ ).

(3) Analysing the results of the numerical simulation, the optimized fuzzy controls are more efficient than the human experience fuzzy control in reducing each layer's peak displacement and acceleration and the average peak displacement and acceleration of the three seismic waves. Comparing with GA-FLC proves that FGA and FPSO are effective.

\section{Conflicts of Interest}

The authors declare no potential conflicts of interest with respect to the research, authorship, and/or publication of this article.

\section{Acknowledgments}

The authors disclosed receipt of the following financial support for the research, authorship, and/or publication of this 
article: this research was supported by the Science Challenge Project of China (Grant no. JCKY2016212A506-0104).

\section{References}

[1] X. Zhao, Z. Hou, and Y. Du, "Design and research of the multidegree-of-freedom damping MR damper," Journal of Earthquake Engineering and Engineering Vibration, vol. 31, no. 5, pp. 178-183, 2011 (Chinese).

[2] M. Bitaraf, O. E. Ozbulut, S. Hurlebaus, and L. Barroso, "Application of semi-active control strategies for seismic protection of buildings with MR dampers," Engineering Structures, vol. 32, no. 10, pp. 3040-3047, 2010.

[3] H.-S. Kim and P. N. Roschke, "Design of fuzzy logic controller for smart base isolation system using genetic algorithm," Engineering Structures, vol. 28, no. 1, pp. 84-96, 2006.

[4] S. F. Ali and A. Ramaswamy, "Optimal fuzzy logic control for MDOF structural systems using evolutionary algorithms," Engineering Applications of Artificial Intelligence, vol. 22, no. 12, pp. 407-419, 2009.

[5] A. S. Ahlawat and A. Ramaswamy, "Multiobjective optimal fuzzy logic controller driven active and hybrid control systems for seismically excited nonlinear buildings," Journal of Engineering Mechanics, vol. 130, no. 4, pp. 416-423, 2004.

[6] A. I. Dounis, P. Tiropanis, G. P. Syrcos, and D. Tseles, "Evolutionary fuzzy logic control of base-isolated structures in response to earthquake activity," Structural Control and Health Monitoring, vol. 14, no. 1, pp. 62-82, 2007.

[7] S. F. Ali and A. Ramaswamy, "GA-optimized FLC-driven semiactive control for phase-II smart nonlinear base-isolated benchmark building," Structural Control and Health Monitoring, vol. 15 , no. 5, pp. 797-820, 2008.

[8] M. Ranjani and P. Murugesan, "Optimal fuzzy controller parameters using PSO for speed control of Quasi-Z Source DC/DC converter fed drive," Applied Soft Computing Journal, vol. 27, pp. 332-356, 2015.

[9] M. Marinaki, Y. Marinakis, and G. E. Stavroulakis, "Fuzzy control optimized by PSO for vibration suppression of beams," Control Engineering Practice, vol. 18, no. 6, pp. 618-629, 2010.

[10] S. Feng, W. Hui, and Y. Lei, Analysis of Matlab intelligent algorithm in 30 cases, Beijing University of Aeronautics and Astronautics Press, Beijing, China, 2011. 


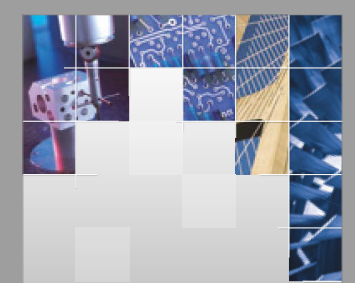

\section{Enfincering}
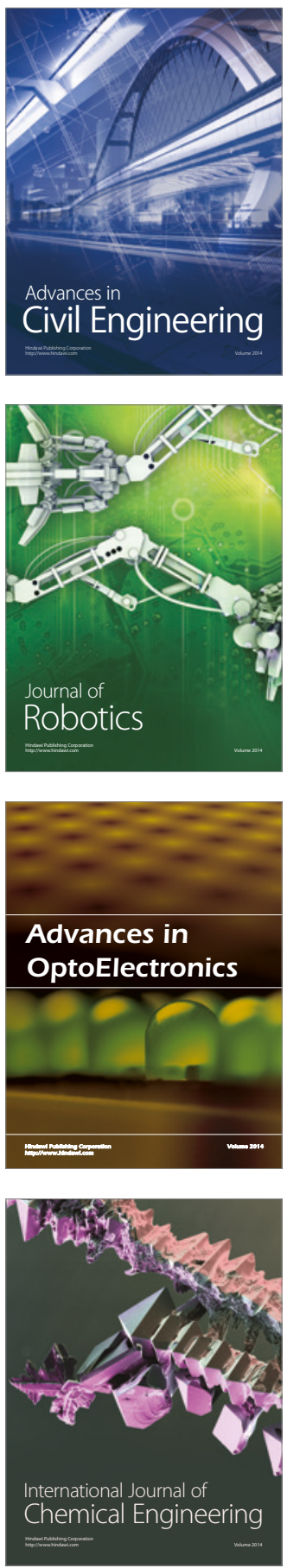

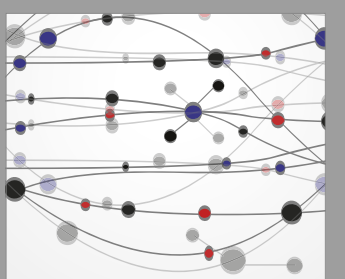

The Scientific World Journal

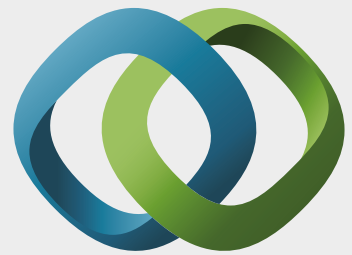

\section{Hindawi}

Submit your manuscripts at

https://www.hindawi.com
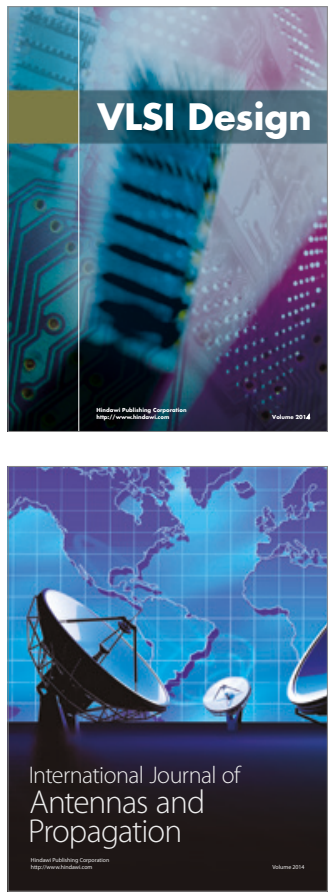

\section{Rotating}

Machinery
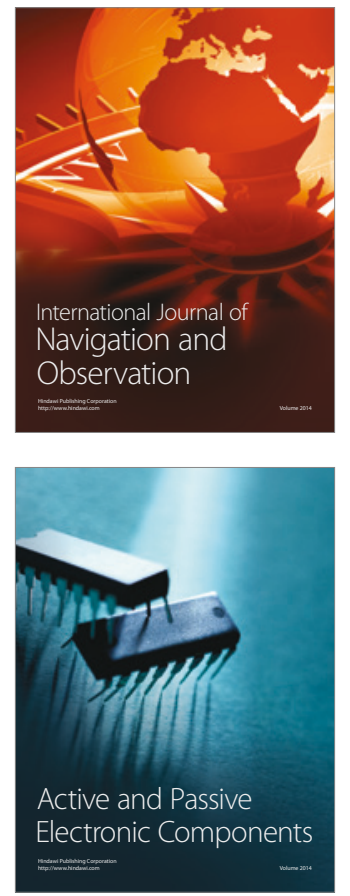
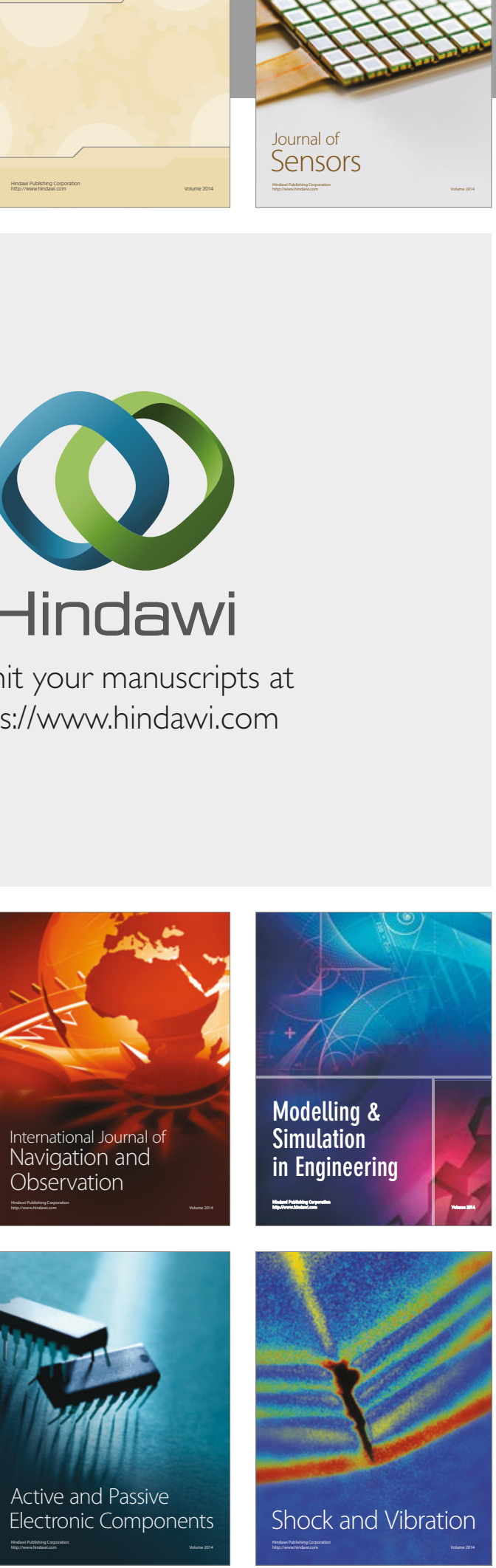
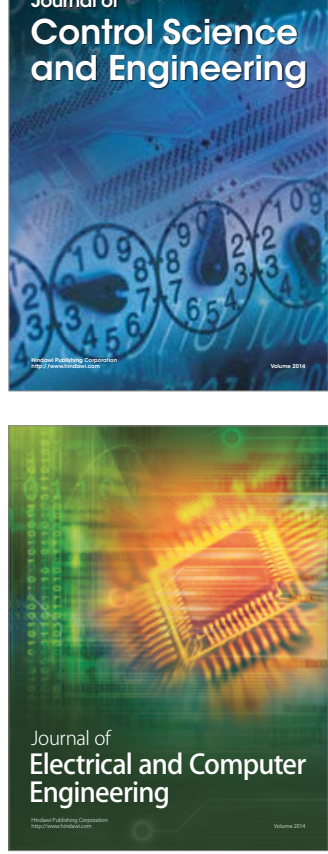

Distributed

Journal of

Control Science

and Engineering
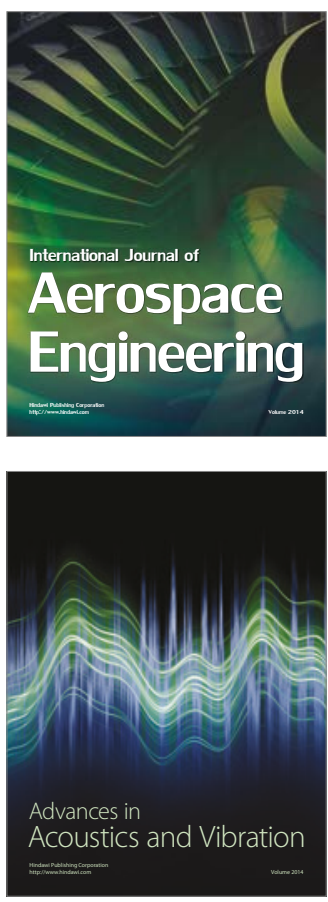

Sensor Networks 